\title{
Do Gender and Education Status of Patients Impact on Quality of their Life after Myocard Infarction
}

\begin{abstract}
Objectives: The aim of this study was to evaluate whether gender and education status of patients impact on quality of their life after myocard infarction.
\end{abstract}

Methods: This cross sectional study included 170 patients who applied to cardiology policlinic in a state hospital Malatya, Turkey. Patients with a history of myocard infarction were included between February and May, 2016.

Results: The mean age was $63.88 \pm 7.8,60 \%$ of the patients were male and $40 \%$ of the patients were female. $24.1 \%$ of the patients were illiterate, $52.4 \%$ of the patients were graduated from primary school and $23.5 \%$ was graduated from high school and over. There were significant differences between QLI total scores and education status of patients $(\mathrm{p}=0.032)$. Women performed lower QLI total scores than men although not statistically significant except family subscale $(\mathrm{p}=0.108)$. Family scores of men were higher than women ( $\mathrm{p}=0.017)$. It was shown that as education level of patients increases, their SF-36 total scores have increased $(\mathrm{p}=0.000)$. Similarly, SF-36 total scores of men were higher than women ( $\mathrm{p}=0.027)$.

Conclusion: The study demonstrated that gender and education levels of patients effected the quality of life according to SF-36 scale. Education levels of patients were the only determinant factor according to OLI scale.

Keywords: Health related quality of life; Gender differences; Chronic heart failure; Education level; Myocard infarction

Research Article
Volume 7 Issue 1 - 2018
Pinar Soylar1* and Ali Ozer ${ }^{2 \#}$
${ }^{1}$ Health Sciences Faculty, Firat University, Turkey
${ }^{2}$ Medicine Faculty, Inonu University, Turkey
*Corresponding author: Pinar Soylar, Health Sciences
Faculty, Firat University, 23119, Elazig, Turkey,
Email: psoylar@gmail.com; aliozer91@hotmail.com
Received: February 05, 2018 | Published: February 16,
2018

\section{Introduction}

Cardiovascular disease is the most important cause of noncommunicable disease (NCD) deaths and is responsible for 17.5 million deaths, or $46 \%$ of NCD deaths. Of these deaths, likely 7.4 million are due to heart attacks (ischemic heart disease) [1]. Women have more risk than men and the risk of individuals increases with age [2]. Cardiovascular disease is also a leading cause of morbidity and mortality in Turkey. The coronary heart disease is most prevalent chronic disease in our country [3]. Quality of life (QOL) is progressively considered as a sign of health care quality, and important component of treatment programs [46]. Physical, social and psychological constrains may impair the quality of life of the patient after myocard infarction. Therefore, treatment aim at increasing well being not longer life [7]. A disease-specific measure of cardiovascular disease Ferrans and Powers' Quality of Life Index Cardiac Version-IV (QLI), a global general health status measure Short Form-36 (SF-36), may often provide insight about health status.

Studies showed that patients with cardiac diseases have been shown to be fewer satisfied with their lives than other chronic disease. Most of the patients experience symptoms as shortness of breath and fatigue, which interfere with daily activities and often have a tremendous impact on the quality of life. The quality of life is much lower compared to healthy individuals and other diseases [8-10]. In addition to first mycocard infarction, patients face noticeably greater risk of recurrent infarctions. The presence of this risk alone is known to considerably impair quality of life [11]. Functional status is poorer in people after heart failure [12-14]. Being a man or a woman has a powerful determinant on health, due to both biological and gender-related differences. Heart disease, often is considered to be a "male" problem, but it causes of death mainly among women $[15,16]$. No matter where they live the number one killer is cardiovascular disease in women. Cardiovascular diseases explain $46 \%$ of older women's deaths worldwide [17]. Socio-demographic and lifestyle factors may explain an extensive part of the differences between women and men in quality of life [18]. Gender and education status of patients impact their health after being diagnosed as a chronic disease patient. Education level of people may effect health related behaviors and increase self care abilities. These people evaluate their status properly and make appropriate healthcare and lifestyle choices. Patients with low literacy level may have trouble reading and writing skills and also to understand basic health information [19].

Given the rising prevalence of cardiovascular disease in Turkey, there is an urgent need to build up effective interventions to improve the QOL of patients. In Turkey, especially east part of country, the percentage of illiterate women higher than men [20]. There were limited studies comparing quality of life both gender and education status. This study was conducted east part of Turkey and aimed to evaluate the quality of life patients 
after myocard infarction according to both gender and education status.

\section{Methods}

\section{Study design}

A cross-sectional research was designed to evaluate health related quality of life in patients with chronic heart failure.

\section{Setting and samples}

This study was conducted Malatya State Hospital. The sample size was calculated as 170 using the formulation for minimum sample size in the condition with a known-population size. Patients who applied to cardiology policlinic after myocard infarction included in this study. Patients who have suffered myocard infarction at least 6 months and more past were included. Patients had mental disabilities or less than 6 months past after myocard infarction were excluded.

\section{Measurement}

The questionnaire consisted of three sections. First section was related to demographic characteristics, second was Ferrans and Powers' Quality of Life Index Cardiac Version- IV and the last was Short Form 36 scale.

\section{Short-form health survey (SF-36)}

This generic instrument consists of 36 questions divided into the following domains: physical functioning, role-physical, pain, vitality (four items), general health perception (five items), role-emotional (three items), social functioning (two items) and mental health (five items). Each dimension is individually analyzed and the scores of the eight components may range from 0 to 100 to a final score. Low scores indicate poor QOL. The range of 0-20 represents a very bad QOL, 20-40 represents a bad $Q O L$, 40-60 moderate, 60-80 good and optimal 80-100 [21].

Ferrans and powers' quality of life index cardiac version- IV

The Ferrans and Powers' quality of life index (QLI)- cardiac version-IV consists of 70 questions divided in to 2 equal parts; part 1 assesses the satisfaction of the patients with various life domains; and part 2 assesses the importance of these domains to the patient. Scores on part 1 were weighted by the responses on part 2. The Ferrans and Powers' Quality of Life Index has 4 sub scales. These are socioeconomic domain, health and functioning, family, psychosocial and spiritual domain [22].

\section{Data collection}

Data was collected from February 01, 2016 to April 30, 2016 Patients were informed about study, aims, study procedure, benefit of the research and confidentiality.

\section{Data analysis}

All statistical analysis were performed using SPSS 21.0 for Windows (SPSS, Chicago, IL, USA). Mann-Whitney U Test, Kruskal-
Wallis, One Way ANOVA and Bonferroni test as post hoc were used in the statistical analysis of the data. $\mathrm{P}<.05$ was considered statistically significant. Data are expressed as mean and standard deviation (SD) unless otherwise stated.

\section{Ethical considerations}

The study protocol was approved by the Institutional Ethics Committee (2016/5-10) and all patients gave written informed consent.

\section{Results}

The socio-demographic characteristics of the patients are shown in Table 1 . The mean age was $63.88 \pm 7.89$, the mean age of female was higher than male (65.13 $\pm 7.96-63.05 \pm 7.77$ respectively). $60 \%$ (102) of the patients were male and $40 \%$ (68) were female. Most of the female patients were housewife and most of the male patients were retired. $52.4 \%$ (89) of the participants had graduated from primary school, $24.1 \%$ (41) were illiterate. The number of illiterate women was two times higher than men (29-12 respectively). $81.9 \%$ (139) were married.

Table 1: The Sociodemographic Characteristics of The Patients.

\begin{tabular}{|c|c|c|c|}
\hline \multicolumn{2}{|c|}{ Sociodemographic Characteristics } & $\mathbf{n}$ & $\%$ \\
\hline \multirow{4}{*}{ Age Groups } & $44-49$ & 6 & 3.5 \\
\hline & $50-59$ & 47 & 27.6 \\
\hline & $60-69$ & 76 & 44.7 \\
\hline & $70-+$ & 41 & 24.1 \\
\hline \multirow{2}{*}{ Sex } & Female & 68 & 40.0 \\
\hline & Male & 102 & 60.0 \\
\hline \multirow{4}{*}{ Marital Status } & Married & 139 & 81.8 \\
\hline & Single & 3 & 1.8 \\
\hline & Widowed & 25 & 14.7 \\
\hline & Divorced & 3 & 1.8 \\
\hline \multirow{5}{*}{$\begin{array}{l}\text { Employment } \\
\text { Status }\end{array}$} & Housewife & 64 & 37.6 \\
\hline & Retired & 44 & 25.9 \\
\hline & $\begin{array}{l}\text { Self Employed/Private } \\
\text { Sector }\end{array}$ & 31 & 18.2 \\
\hline & Officer & 18 & 10.6 \\
\hline & Farmer & 13 & 7.6 \\
\hline \multirow{4}{*}{ Education Level } & Illiterate & 41 & 24.1 \\
\hline & Primary School & 89 & 52.4 \\
\hline & High School & 25 & 14.7 \\
\hline & University & 15 & 8.8 \\
\hline
\end{tabular}




\section{Ferrans and powers' quality of life Index cardiac version- IV scores (QLI)}

Table 2 presents QLI scores of patients by their education status. There were statistically significant differences between Health and Functioning - Social and Economic subscales and patients' education status ( $\mathrm{p}=.037$ and $\mathrm{p}=.008$ respectively). It was shown that as education level of people increased, the scores of both subscales increased. No significant differences were found between Psychologic and Sipiritual - Family subscale scores by patients' education status. The distribution of OLI scores by gender are presented in Table 3. OLI scores of men were higher than women in all sub groups. There were statistically significant differences between the family sub groups score and gender $(\mathrm{p}=$ .017).

Table 2: The Distributions of OLI Scores According to Patient's Educational Status.

\begin{tabular}{|c|c|c|c|c|c|}
\hline \multirow{2}{*}{$\begin{array}{l}\text { Ferrans and Powers' } \\
\text { Quality of Life Index } \\
\text { Scale (OLI) }\end{array}$} & \multirow{2}{*}{$\begin{array}{l}\text { Illiterate } \\
\text { Mean (SD) }\end{array}$} & \multirow{2}{*}{$\begin{array}{c}\text { Primary School } \\
\text { Mean (SD) }\end{array}$} & \multirow{2}{*}{$\begin{array}{l}\text { High School } \\
\text { Mean (SD) }\end{array}$} & \multicolumn{2}{|c|}{ University } \\
\hline & & & & Mean (SD) & $P$ value* \\
\hline Health and Functioning (HF) & $14.31 \pm 4.63$ & $16.75 \pm 4.95$ & $16.20 \pm 3.36$ & $17.46 \pm 4.53$ & 0.037 \\
\hline Family (F) & $13.95 \pm 3.41$ & $15.89 \pm 3.83$ & $15.56 \pm 2.55$ & $16.73 \pm 3.59$ & 0.057 \\
\hline Social and Economic (SE) & $13.92 \pm 3.00$ & $15.44 \pm 3.14$ & $14.48 \pm 2.50$ & $16.60 \pm 2.44$ & 0.008 \\
\hline Psychologic and Sipiritual (PS) & $15.60 \pm 2.77$ & $16.93 \pm 3.15$ & $16.92 \pm 2.67$ & $17.26 \pm 2.15$ & 0.074 \\
\hline Total & $57.80 \pm 12.43$ & $65.03 \pm 13.57$ & $63.16 \pm 8.93$ & $68.06 \pm 11.41$ & 0.032 \\
\hline
\end{tabular}

*Kruskall Wallis, SD: Standard Deviation

Table 3: The Distributions of OLI Scores According to Patient's Gender.

\begin{tabular}{|c|c|c|c|}
\hline $\begin{array}{c}\text { Ferrans and Powers' } \\
\text { Quality of Life Index } \\
\text { Scale }\end{array}$ & $\begin{array}{c}\text { Male } \\
\text { Mean (SD) }\end{array}$ & $\begin{array}{c}\text { Female } \\
\text { Mean (SD) }\end{array}$ & P value* \\
\hline Health and Functioning (HF) & $16.54 \pm 4.61$ & $15.54 \pm 4.86$ & 0.186 \\
\hline Family (F) & $16.01 \pm 3.80$ & $14.60 \pm 3.20$ & 0.017 \\
\hline Social and Economic (SE) & $15.28 \pm 3.14$ & $14.67 \pm 2.90$ & 0.268 \\
\hline $\begin{array}{c}\text { Psychologic and Sipiritual } \\
\text { (PS) }\end{array}$ & $16.93 \pm 2.98$ & $16.20 \pm 2.88$ & 0.098 \\
\hline Total & $64.78 \pm 12.95$ & $61.02 \pm 12.49$ & 0.108 \\
\hline
\end{tabular}

*Mann Whitney U Test, SD: Standard Deviation

\section{Short-form health survey (SF-36) scores}

SF 36 scores of patients by their education levels are presented in Table 3. While education level of patients were increasing it was shown that their scores of subscales increased except bodily pain $(\mathrm{p}<.005)$. Although the bodily pain scores increased by their education levels there was no statistically significant difference $(p=.211)$. Women performed worse almost in all subscales in comparison with males. The total scores of men better than women ( $p=.027)$. The PF, GH and V scores of men were higher than women ( respectively $\mathrm{p}=.021, \mathrm{p}=.047, \mathrm{p}=.002$ ).

\section{Discussion}

The current study was conducted to evaluate the factors that are associated with the QOL of patients after myocard infarction. In this study, we used the QLI and SF 36 to measure the QOL of patients. Previous studies have shown that QOL of the patients after myocard infarction is associated with patient characteristics (e.g. gender, age and employment status) [23-25]. The patients who have high school or university degree had higher QOL scores than those graduated from other educational levels in all domains of the SF 36 scale except bodily pain. The patients who have high school or university degree had greater social and economic, health and functional scores than those graduated from other educational levels in QLI scale. Our finding is similar a study that conducted in Turkey. It reported that education status of patient is associated with QOL post-myocard infarction [26]. Educational status of patients may affect their self care management. Illiterate patients and also patients with low literacy may have trouble understand basic health information and treatment-seeking behavior [27].

Gender was a vital factor for QOL in patient's post-myocard infarction in this study. It can be seen some specific differences such as disease related factors, self care management and medical adherence as a result of different roles taken by gender. 
In accordance with previous study, women had an unfavorable QOL after myocard infarction [28-30]. Although there was not statistically significant difference between gender and QLI scores, women had poorer scores than men. Surprisingly, in family domain of the QLI scale men had higher QOL than women. We found that the mean age of women was higher than men and most of the female patients were housewife. Lower educational level, not having a career, lower income was associated with poorer
QOL in women [28]. In this study, physical function and vitality dimensions of SF 36 scale were significantly lower in women than in men. This result is consistent with studies $[29,30]$.

The results of the present study indicated that QOL of the patient was associated with gender and educational level. Higher educational level and being men increase QOL. Taking into account the role of quality life is an important part of heart failure management (Table 4\&5).

Table 4: The Distributions of SF 36 Scores According to Patient's Educational Status.

\begin{tabular}{|c|c|c|c|c|}
\hline SF 36 Scale & $\begin{array}{c}\text { Illiterate } \\
\text { Mean (SD) }\end{array}$ & $\begin{array}{c}\text { Primary School } \\
\text { Mean (SD) }\end{array}$ & $\begin{array}{c}\text { High School } \\
\text { Mean (SD) }\end{array}$ & $\begin{array}{c}\text { University } \\
\text { Mean (SD) }\end{array}$ \\
\hline Physical Functioning (PF) & $42.56 \pm 18.57$ & $61.46 \pm 17.45$ & $68.80 \pm 14.30$ & $75.66 \pm 8.83$ \\
\hline Role Physical (RP) & $24.08 \pm 12.92$ & $30.05 \pm 13.01$ & $37.00 \pm 11.68$ & $35.83 \pm 10.42$ \\
\hline Bodily Pain (BP) & $62.75 \pm 24.06$ & $69.16 \pm 19.08$ & $68.68 \pm 16.24$ & $75.63 \pm 16.37$ \\
\hline General Health (GH) & $45.73 \pm 14.77$ & $56.12 \pm 13.72$ & $55.00 \pm 12.58$ & $61.33 \pm 11.25$ \\
\hline Vitality (V) & $35.48 \pm 14.30$ & $47.97 \pm 13.97$ & $52.20 \pm 17.02$ & $57.33 \pm 9.61$ \\
\hline Social Functioning (SF) & $41.15 \pm 25.34$ & $55.89 \pm 25.84$ & $69.50 \pm 15.76$ & $76.66 \pm 18.21$ \\
\hline Role Emotional (RE) & $36.82 \pm 16.99$ & $39.32 \pm 13.34$ & $47.96 \pm 5.63$ & $46.60 \pm 7.03$ \\
\hline Mental Health (MH) & $44.40 \pm 15.56$ & $53.31 \pm 13.79$ & $56.80 \pm 13.06$ & 0.001 \\
\hline Total & $333.01 \pm 106.73$ & $413.32 \pm 94.41$ & $455.94 \pm 75.32$ & $487.20 \pm 47.95$ \\
\hline
\end{tabular}

*Kruskall Wallis, SD: Standard Deviation

Table 5: The Distributions of OLI Scores According to Patient's Gender.

\begin{tabular}{|c|c|c|c|}
\hline SF 36 Scale & $\begin{array}{c}\text { Male } \\
\text { Mean (SD) }\end{array}$ & $\begin{array}{c}\text { Female } \\
\text { Mean (SD) }\end{array}$ & $\begin{array}{c}\text { P } \\
\text { value* }\end{array}$ \\
\hline $\begin{array}{c}\text { Physical Functioning } \\
\text { (PF) }\end{array}$ & $61.51 \pm 19.97$ & $55.80 \pm 18.60$ & 0.021 \\
\hline Role Physical (RP) & $30.14 \pm 13.55$ & $30.14 \pm 12.81$ & 0.815 \\
\hline Bodily Pain (BP) & $69.77 \pm 19.35$ & $65.63 \pm 20.76$ & 0.213 \\
\hline General Health (GH) & $55.68 \pm 14.75$ & $51.25 \pm 13.44$ & 0.047 \\
\hline Vitality (V) & $49.60 \pm 14.65$ & $41.61 \pm 15.96$ & 0.002 \\
\hline Social Functioning (SF) & $57.84 \pm 25.30$ & $53.67 \pm 27.23$ & 0.242 \\
\hline Role Emotional (RE) & $40.37 \pm 14.14$ & $41.02 \pm 12.86$ & 0.959 \\
\hline Mental Health (MH) & $53.88 \pm 13.62$ & $49.42 \pm 15.31$ & 0.104 \\
\hline Total & $418.83 \pm 103.35$ & $388.59 \pm 100.49$ & 0.027 \\
\hline
\end{tabular}

*Mann Whitney U Test, SD: Standard Deviation

Our study had some limitations. Only patients who were living in the east part of Turkey were included in this study. Considering the role of women in house or business, it may differ from other regions of Turkey. There were some confounding factors such as co-morbidity, age, physical activity rate may affect the quality of life after myocard infarction. Also, not using New York Heart
Association NYHA class is an important limitation of the study that might be contributed to low scores in QOL. Despite these limitations, our findings are important because there are little studies in Turkey emphasizing relationship between sociodemographic factors and quality of life after myocard infarction. It is suggested that study samples may enhance including patients from other geographic areas in further researches. Future intervention programs should be designed to improve quality of life mainly the weakest groups among patients. Improving lifestyle factors and reducing educational disparities and gap among gender equity would help patients for increasing quality of life.

\section{Conflict of Interest}

The authors declare that they have no conflict interest. This study was accepted as a poster $10^{\text {th }}$ European Public Health Conference in Stockholm, Sweden.

\section{Acknowledgment}

We would like to thank the General Secretary of the Public Hospitals Union Malatya, Turkey.

\section{Funding}

This study did not obtain any specific grant from financial support agencies in the public, profit or not-for-profit sectors. 


\section{References}

1. World Health Organization (2014) Global Status Reports on Noncommunicable Diseases. Geneva (Swiss).

2. World Health Organization (2011) Cardiovascular Disease CVD prevention and control: missed opportunities.

3. Kurcer MA, Ozbay A (2011) Effects of patient education and counseling about life style on quality of life in patients with coronary artery disease. Anadolu Kardiyol Derg 11(2): 107-113.

4. Austin J, Williams WR, Hutchison S (2009) Multidisciplinary management of elderly patients with chronic heart failure: five year outcome measures in death and survivor groups. Eur J Cardiovasc Nurs 8(1): 34-39.

5. Jaarsma T, Beattie JM, Ryder M, Rutten FH, Mc Donagh T, et al. (2009) Advanced Heart Failure Study Group of the HFA of the ESC et al. Palliative care in heart failure: a position statement from the palliative care workshop of the heart failure association of the european society of cardiology. Eur J Heart Fail 11(5): 433-443.

6. Lindenfeld J, Albert NM, Boehmer JP, Collins SP, Ezekowitz JA, et al (2010) HFSA 2010 comprehensive heart failure practice guideline. J Card Fail 16(6): e1-194.

7. Thompson DR, Jenkinson C, Roebuck A, Lewin RJ, Boyle RM, et al. (2002) Development and validation of a short measure of health status for individuals with acute myocardial infarction: the myocardial infarction dimensional assessment scale (MIDAS). Qual Life Res 11(6): 535-543.

8. Cully JA, Phillips LL, Kunik ME, Stanley MA, Deswal A (2010) Predicting quality of llife in veterans with heart failure: the role of disease severity, depression, and comorbid anxiety. J Behav Med 36(2): 70-76

9. Cohn JN (1997) Current concepts in the treatment of congestive heart failure. Cardiology 88(Suppl 2): 2-6.

10. Mc Sweeny AJ, Creer TL (1995) Health-related quality of life assessment in medical care. Dis Mon 41(1): 1-71.

11. World Health Organization (2013) Prevention of recurrent heart attacks and strokes in low and middle income populations: evidencebased recommendations for policy makers and health professionals.

12. Flanagan S, Damery S, Combes G (2017) The effectiveness of integrated care interventions in improving patient quality of life (QoL) for patients with chronic conditions. An overview of the systematic review evidence. Health Qual Life Outcomes 15(1): 188.

13. Dracup K, Walden JA, Stevenson LW, Brecht ML (1992) Quality of life in patients with advanced heart failure. J Heart Lung Transplant 11(2 Pt 1): 273-9.

14. Hawthorne MH, Hixon ME (1994) Functional status, mood disturbance and quality of life in patients with heart failure. Progr Cardiovasc Nurs 9(1): 22-32.

15. Simon T, Mary-Krause M, Funck-Brentano C, Jaillon P (2001) Sex differences in the prognosis of congestive heart failure: results from the cardiac insufficiency bisoprolol study (CIBIS II). Circulation 103(3): 375-380
16. Vaccarino V, Chen YT, Wang Y, Radford MJ, Krumholz HM (1999) Sex differences in the clinical care and outcomes of congestive heart failure in the elderly. Am Heart J 138(5 Pt 1): 835-842.

17. World Health Organization (2007) Women, Ageing and Health: A Framework for action: focus on gender.

18. Guallar-Castillon P, Sendino AR, Banegas JR, Garcia EL, Artalejo FR (2005) Differences in quality of life between women and men in the older population of spain. Soc Sci Med 60(6): 1229-1240.

19. Stockdale-Whoolley $\mathrm{T}$ (1984) The effects of education and support on self-care agency. Public Health Nurs 1(2): 97-106.

20. 2016 Turkish Statistical Institute.

21. Ulbrich AZ, Angarten VG, Netto AS, Sties SW, Bundchen, et al. (2016) Comparative effects of high intensity interval training versus moderate intensity continuous training on quality of life in patients with heart failure: Study protocol for a randomized controlled trial. Clin Trials Regul Sci Cardiol 13: 21-8.

22. Canli ZO, Akdemir N (2003) The validity and reliability of the study on "ferrans and powers' quality of life scale" in the patients who had myocardial infarction.

23. Cully JA, Phillips LL, Kunik ME, Stanley MA, Deswal (2010) Predicting Quality of Life in Veterans with Heart Failure: The Role of Disease Severity, Depression, and Comorbid Anxiety. J Behav Med 36(2): 7076.

24. Kato N, Kinugawa K, Seki S, Shiga T, Hatano M, et al. (2011) Quality of life as an independent predictor for cardiac events and death in patients with heart failure. Circulation 75(7): 1661-1669.

25. Lee H, Boo S, Yu J, Suh SR, Chun KJ, et al. (2017) Physical functioning, physical activity, exercise self-efficacy, and quality of life among individuals with chronic heart failure in Korea: a cross-sectional descriptive study. J Nurs Res 25(2): 131-139.

26. Blinderman CD, Homel P, Billings JA, Tennstedt S, Portenoy RK (2009) Symptom Distress and Quality of Life in Patients with Advanced Chronic Obstructive Pulmonary Disease. J Pain Symptom Manage 38(1): 115-123.

27. Dickson V, Chyun D, Caridi C, Gregory JK, Katz S (2016) Low literacy self-care management patient education for a multi-lingual heart failure population: Results of a pilot study. Appl Nurs Res 29: 122124.

28. Rahnavard Z, Nodeh ZH, Hatamipour K (2014) Congestive heart failure: Predictors of health-related quality of life in iranian women. Contemp Nurse 47(1-2): 159-167.

29. Orfilaa F, Ferrera M, Lamarcaa R, Tebe C, Domingo-Salvany A, et al. (2006) Gender differences in health-related quality of life among the elderly: the role of objective functional capacity and chronic conditions. Soc Sci Med 63(9): 2367-2380.

30. Riegel B, Moser D, Carlson B, Deaton C, Armola R, et al. (2003) Gender differences in quality of life are minimal in patients with heart failure. J Card Fail 9(1): 42-48. 